\title{
Decreases in the number and severity of morphometrically defined vertebral body deformities after kyphoplasty
}

\author{
Jon T. LedLIE, M.D., AND MARK B. ReNFro, M.D. \\ Tyler Neurosurgical Associates, Tyler, Texas
}

\begin{abstract}
Object. Vertebral body (VB) deformities have been associated with increased patient morbidity and mortality rates. The aim of this retrospective, consecutive single-center cohort study was to determine the effectiveness of kyphoplasty in reducing morphometrically defined VB deformity, including deformity shape types (wedge, biconcave, or crush) and grade (severity).

Methods. The authors identified 100 patients (70\% women; mean age 76.1 years) in whom 138 vertebral fractures (T-4 through L-5; mean fracture age 2.7 months) that were treated between May 2000 and December 2001 were radiographically evaluated preoperatively and at the last follow-up visit (mean follow-up duration 16.9 months). Fractures were divided into four groups by level: T5-9 (28 fractures), T10-12 (41), L1-2 (42), and L3-5 (27). Anterior, midline, posterior, and predicted posterior vertebral heights for fractured and adjacent unfractured reference vertebrae were measured on lateral radiographs. The deformity type and grade were mathematically defined using the modified methods of McCloskey-Kanis and Black.

The total number of deformities decreased from 89.9 to $53.6 \%$ after kyphoplasty $(\mathrm{p}<0.0001)$. The number of fractures with wedge, biconcave, or crush deformity decreased 22.5, 59.1, and 67.7\% $(p=0.0699, p=0.0222, p=0.0007)$, respectively. The number of the more severe Grade 2 deformities decreased (79.7 to 37.0\%; $\mathrm{p}<0.0001$ ). Kyphoplasty effectively decreased the number of deformed fractures in all vertebral level groups $(\mathrm{T} 5-9, \mathrm{p}=0.0023 ; \mathrm{T} 10-12$, $\mathrm{p}=$ 0.0105; L1-2, p $<0.0001 ; \mathrm{L} 3-5$, p = 0.0028).

Conclusions. Kyphoplasty resulted in significant normalization of vertebral shapes in patients with symptomatic vertebral fractures, reducing the number and severity of deformed fractures postoperatively.
\end{abstract}

\section{KEY WORDS • vertebral deformity • vertebral fracture • kyphoplasty • morphometric measurement}

It is becoming increasingly clear that adverse clinical outcomes in patients with vertebral fractures are related to the severity of VB deformity. Reductions in pulmonary function (vital capacity and timed forced expiratory volume) have been shown to correlate with clinical and radiological findings for the severity of spinal deformation due to osteoporotic fractures. ${ }^{22}$ Health outcome indicators, including intensity of current and previous back pain, functional capacity (activities of daily living questionnaire), and overall subjective health show that the magnitude of negative associations increases with the severity and number of vertebral deformities. ${ }^{12}$ Thoracic curvature has been significantly correlated with age $(r=-0.48, p<0.001)$ and with the vertebral deformity index $(r=0.6, p<0.001)$ in patients with vertebral fractures. ${ }^{3}$

Vertebral deformity is also associated with modest excess mortality rates, particularly in women. Only part of this excess can be explained by other adverse health and lifestyle factors linked to mortality rates. ${ }^{9}$ Vertebral defor-

\footnotetext{
Abbreviations used in this paper: $\mathrm{Ha}=$ anterior height; $\mathrm{Hm}=$ midline height; $\mathrm{Hp}=$ posterior height; $\mathrm{Hpp}=$ predicted $\mathrm{Hp} ; \mathrm{SD}=$ standard deviation; $\mathrm{VB}=$ vertebral body.
}

mities in older women with low bone mass are associated with increased risks of death and hospitalization, but only a portion of this increased risk was explained by other known predictors of these outcomes. ${ }^{5}$ Vertebral deformity accompanied by a reduction in vertebral height is associated with decreased maximum peak expiratory flow, decreased grip strength, and more than 3 days with limited activities in the course of a month. ${ }^{19} \mathrm{~A}$ vertebral deformity with a reduction of greater than 3 SDs in vertebral height ratio was found to predict death during the forthcoming decade in both men (age-adjusted hazard ratio 2.4; $95 \%$ confidence interval 1.6-3.9) and women (age-adjusted hazard ratio $2.3 ; 95 \%$ confidence interval $1.3-4.3){ }^{8}$ The risk of a subsequent vertebral fracture in patients with an existing deformity is influenced by the shape and severity of a prevalent deformity and is greater for adjacent vertebrae, suggesting a mechanical component. ${ }^{11}$ Testing the hypothesis that the characteristics of a baseline deformity would influence the size of a subsequent one, Reeve and colleagues $^{21}$ found that the number of baseline deformities and the clinical category of the most severe baseline deformity were associated with the size of the most severe incident fracture and with the cumulated sum of all vertebral height losses. 
Ettinger and colleagues ${ }^{6}$ have shown that wedge, biconcave, and crush vertebral deformities 4 SDs or more below the mean in the population were associated with a risk of moderate to severe back pain that was 1.9 times higher, a risk of disability involving the back that was 2.6 times higher, and a risk of losing $4 \mathrm{~cm}$ or more of height that was 2.5 times higher. Similarly, Ismail and colleagues ${ }^{9}$ reported that wedge, biconcave, and crush deformities were associated with height loss, back pain, and other adverse outcomes; crush deformities resulted in the greatest height loss.

Kyphoplasty is a relatively new technique for fracture reduction, with published results documenting a sustained improvement (at least 1 year) for pain alleviation, increased ambulation, correction of kyphosis, and restoration of collapsed vertebral height. ${ }^{10,18}$ Nevertheless, the relationship of the fracture reduction produced by kyphoplasty treatment to standard definitions of deformity has not been previously established. ${ }^{7,10,18}$ In this study we report the effect of kyphoplasty treatment of symptomatic vertebral fractures by using quantitative morphometric measures of vertebral deformity.

\section{CLINICAL MATERIAL AND METHODS}

\section{Patients and Procedures}

Between May 2000 and December 2001, kyphoplasty procedures were performed in 119 consecutive patients in this retrospective single-center study. All patients presented with severe pain and failure of standard medical therapy, and all provided informed consent. Eligibility criteria and procedural details have been described earlier. ${ }^{10}$ Nineteen patients were excluded because their $\mathrm{x}$-ray films were not available. The results are reported for the remaining 100 patients $(70 \%$ women; mean age 76.1 years, range 51-93 years), in whom 138 painful vertebral fractures (T4 through L-5) were treated with 108 kyphoplasty procedures. Osteoporosis was associated with fractures in 98\% of patients. Fracture age (129 fractures; mean 2.7 months, range 2 days-14 months, median 1.9 months) was calculated as the time from symptom onset (when available) to surgery.

\section{Radiographic Measurement}

Preoperatively and at the last follow-up visit (mean follow-up duration 16.9 months, range 12 days-27.6 months) lateral radiographs were evaluated for each patient. Six-point semiquantitative VB height measurements $(\mathrm{Hp}, \mathrm{Hm}$, and $\mathrm{Ha}$ ) were recorded for the fractured vertebra and the nearest unfractured, adjacent cephalad and caudad reference vertebrae. The Hpp was obtained from the mean Hp of the reference vertebrae.

\section{Deformity Determinations}

To determine the degree of treatment effect among the varying types of vertebral shapes (Fig. 1) and grades of severity, various height ratios $(\mathrm{Ha} / \mathrm{Hp}, \mathrm{Ha} / \mathrm{Hpp}, \mathrm{Hm} / \mathrm{Hp}$, $\mathrm{Hm} / \mathrm{Hpp}$, and $\mathrm{Hp} / \mathrm{Hpp}$ ) were derived and applied in a modified McCloskey-Kanis and Black mathematical deformity model to classify vertebral fractures. Individual affected levels were grouped into fracture levels as fol-



lows: T5-9 (28 fractures); T10-12 (41), L1-2 (42), and L3-5 (27) to approximate an even distribution among all levels for reference value determination. The nearest adjacent unfractured vertebrae were measured to obtain reference values $(\mathrm{Ha} / \mathrm{Hp}$ and $\mathrm{Hm} / \mathrm{Hp})$. A gaussian quantilequantile plot was constructed for all $\mathrm{Ha} / \mathrm{Hp}$ and $\mathrm{Hm} / \mathrm{Hp}$ values and used to estimate the SD of all references..$^{13}$ After trimming extreme values, the middle $80 \%$ of values was used to calculate an adjusted mean and SDs. ${ }^{1}$ The Hpp was calculated from the unfractured reference vertebrae's mean height. The deformity threshold was determined using a percentage method that assumed a value of 1.0 for the reference $\mathrm{Hp} / \mathrm{Hpp}$ value. ${ }^{1,13}$

A vertebral deformity was defined as a greater than $20 \%$ reduction from the reference $\mathrm{Hp} / \mathrm{Hpp}$ value $(0.80 \times$ the mean) or a reduction from the reference $\mathrm{Ha} / \mathrm{Hp}$ or $\mathrm{Hm} / \mathrm{Hp}$ greater than 3 SDs. A crush (compression) deformity had an Hp/Hpp less than 0.80 (which equals a > $20 \%$ reduction); a wedge deformity had an $\mathrm{Ha} / \mathrm{Hp}$ and $\mathrm{Ha} / \mathrm{Hpp}$ less than the adjusted reference mean - 3 SDs; and a biconcave (endplate) deformity had an $\mathrm{Hm} / \mathrm{Hp}$ and $\mathrm{Hm} / \mathrm{Hpp}$ less than the adjusted reference mean -3 SDs. A fracture meeting multiple criteria would be classified as crush rather than wedge, and wedge rather than biconcave. ${ }^{13,17,25}$ A Grade 1 deformity had a greater than $20 \%$ but less than or equal to $25 \%$ reduction for $\mathrm{Hp} / \mathrm{Hpp}$ and greater than 3 SDs but less than or equal to 4 SDs below the reference cutoff value for $\mathrm{Ha} / \mathrm{Hp}$ and $\mathrm{Hm} / \mathrm{Hp}$, and a Grade 2 deformity had a greater than $25 \%$ reduction for $\mathrm{Hp} / \mathrm{Hpp}$ or greater than 4 SDs below the reference values for $\mathrm{Ha} / \mathrm{Hp}$ and $\mathrm{Hm} / \mathrm{Hp}^{4}$

\section{RESULTS}

\section{Assessment of Vertebral Deformity}

Vertebral fractures meeting one or more deformity criteria preoperatively (124 [89.9\%] of 138 fractures) de- 
creased to $74(53.6 \%)$ of 138 postoperatively ( $<<0.0001$; Table 1 and Fig. 2). Fractures meeting multiple deformity criteria (104 [75.4\%] of 138) decreased to $25(18.1 \%)$ of $138(\mathrm{p}<0.0001)$, whereas the number of fractures meeting only one deformity criteria (20 [14.5\%] of 138 increased to $49(35.5 \%)$ of 138 ( $\mathrm{p}<0.0001$; Table 1 and Fig. 3). The number of biconcave deformities (22 [15.9\%] of 138) decreased to nine $(6.5 \%)$ of $138(\mathrm{p}=0.0222)$, and crush deformities (31 [22.5\%] of 138) decreased to 10 $(7.2 \%)$ of $138(\mathrm{p}=0.0007)$. The number of wedge deformities (71 [51.4\%] of 138) tended to decrease (55 [39.9\%] of 138) postoperatively ( $\mathrm{p}=0.0699$; Table 1 and Fig. 4). The number of the more severe Grade 2 deformities (110 [79.7\%] of 138$)$ decreased to $51(37 \%)$ of 138 (p < $0.0001)$, whereas Grade 1 deformities (14 [10.1\%] of 138) tended to increase (23 [16.7\%] of 138) $(\mathrm{p}=0.1576$; Table 1 and Fig. 5). Among fracture level groups, the number of deformed fractures ranged from 83.3 to $96.4 \%$ preoperatively and decreased to between 38.1 and $68.3 \%$ postoperatively (T5-9, $\mathrm{p}=0.0023 ; \mathrm{T} 10-12, \mathrm{p}=0.0105 ; \mathrm{L} 1-2$, $\mathrm{p}<0.0001$; L3-5, $\mathrm{p}=0.0028$; Table 1 and Fig. 6).

\section{DISCUSSION}

Findings in this study show that kyphoplasty significantly reduces the number of morphometrically determined deformed fractures and the severity of vertebral deformity. Kyphoplasty resulted in a marked shift from deformed to nondeformed fractures, corrected all three shape classifications of deformity (biconcave, wedge, and crush), and led to a dramatic reduction in the number of fractures meeting multiple classifications of anatomical deformities. In the fractures that continued to be classified as deformed after treatment, there was improvement in all morphometric measures and grade; in particular there was

TABLE 1

Classification and severity of deformity in 100 patients with 138 painful vertebral fractures*

\begin{tabular}{|c|c|c|c|c|}
\hline Factor & $\begin{array}{l}\text { No. of } \\
\text { Preop }\end{array}$ & $\begin{array}{l}\text { Fxs (\%) } \\
\text { Last FU }\end{array}$ & $\mathrm{p}$ Value & $\begin{array}{l}\text { \% Change } \\
\text { Preop to } \\
\text { Last FU }\end{array}$ \\
\hline \multicolumn{5}{|l|}{ fxs } \\
\hline deformed & $124(89.9)$ & $74(53.6)$ & $<0.0001$ & -40.3 \\
\hline multiple defs & $104(75.4)$ & $25(18.1)$ & $<0.0001$ & -76.0 \\
\hline single def & $20(14.5)$ & $49(35.5)$ & $<0.0001$ & 145.0 \\
\hline nondeformed & $14(10.1)$ & $64(46.4)$ & $<0.0001$ & 357.1 \\
\hline \multicolumn{5}{|l|}{ def classification } \\
\hline biconcave & $22(15.9)$ & $9(6.5)$ & 0.0222 & -59.1 \\
\hline crush & $31(22.5)$ & $10(7.2)$ & 0.0007 & -67.7 \\
\hline wedge & $71(51.4)$ & $55(39.9)$ & 0.0699 & -22.5 \\
\hline \multicolumn{5}{|l|}{ def severity } \\
\hline Grade 2 & $110(79.7)$ & $51(37.0)$ & $<0.0001$ & -53.6 \\
\hline Grade 1 & $14(10.1)$ & $23(16.7)$ & 0.1576 & 64.3 \\
\hline \multicolumn{5}{|c|}{ def by fx level group $\dagger$} \\
\hline T5-9 & $27(96.4)$ & $17(60.7)$ & 0.0023 & -37.1 \\
\hline T10-12 & $38(92.7)$ & $28(68.3)$ & 0.0105 & -26.3 \\
\hline L1-2 & $35(83.3)$ & $16(38.1)$ & $<0.0001$ & -54.3 \\
\hline L3-5 & $24(88.9)$ & $13(48.2)$ & 0.0028 & -45.8 \\
\hline
\end{tabular}

$*$ Def = deformity; FU = follow up; $\mathrm{fx}=$ fracture

$\dagger$ There were 28 fractures in the T5-9 group, 41 in the T10-12 group, 42 in the L1-2 group, and 27 in the L3-5 group.

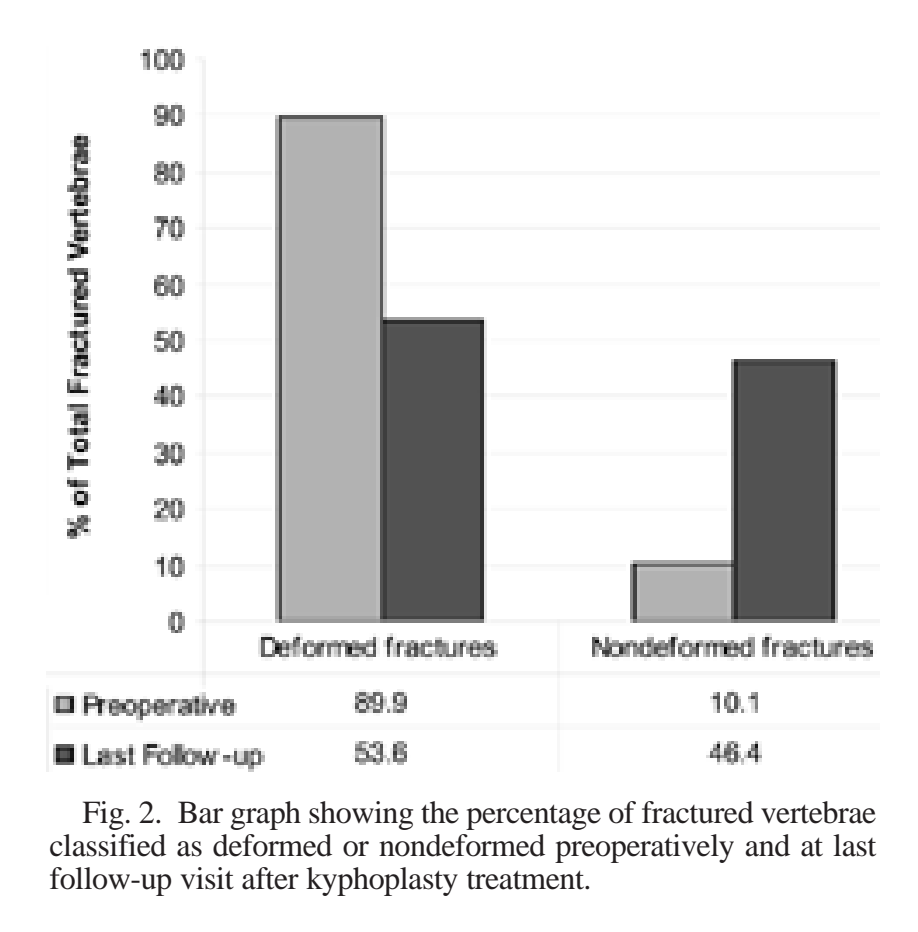

a shift from fractures meeting multiple deformity criteria preoperatively to single-deformity or nondeformed classifications postoperatively, and the more severe Grade 2 deformities were reduced to less severe Grade 1 deformities or placed in the nondeformed category.

To our knowledge, there are no similar morphometric deformity studies of treated vertebral fractures with which to compare these results. Morphometric measures have begun to be used only recently, for quantitative evaluations of the effect of treatments for vertebral fractures. $\mathrm{Na}$ kano and colleagues ${ }^{15}$ report an 11 to $16 \%$ improvement in

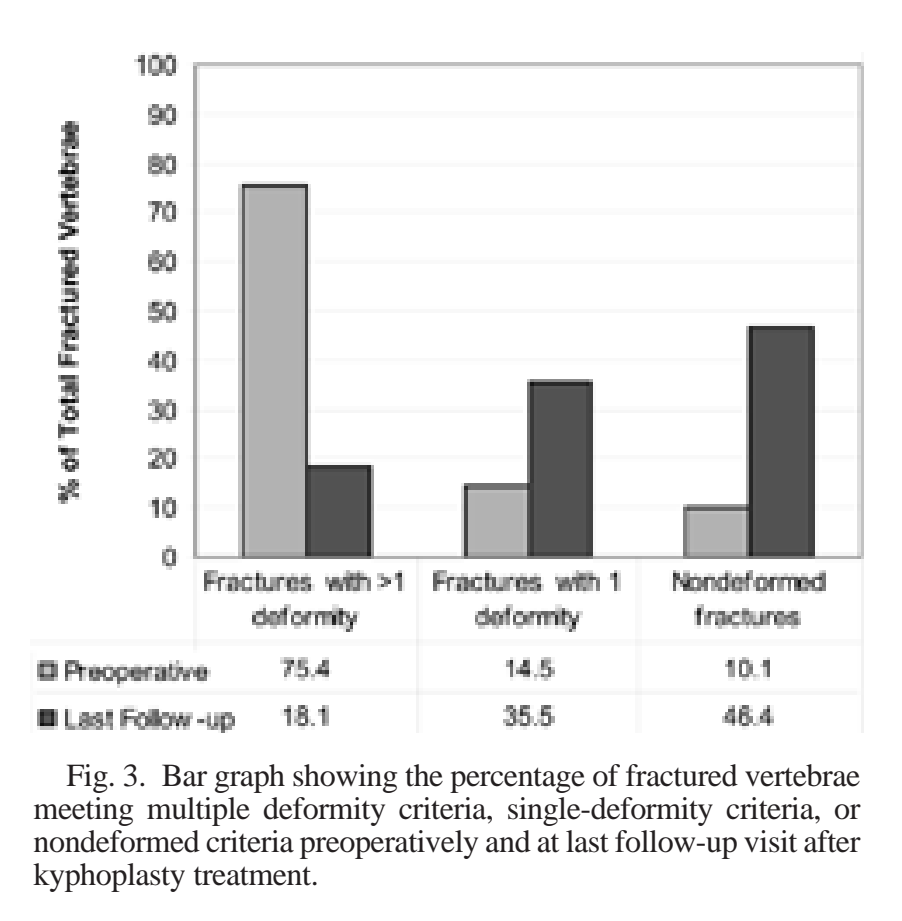






the spinal deformity index expressed as a ratio of the VB height (sum of measurements at the anterior, midline, and posterior regions) to its longitudinal diameter after percutaneous vertebroplasty, but there was no comparison with reference values or morphometrically defined deformity in their study.

It has been suggested that the reference values used for identifying deformities should be derived from within individual populations whenever possible. O'Neill and colleagues ${ }^{16}$ found that the distribution of reference values for vertebral height ratios vary in different population centers, as well as between men and women. Melton, et al., ${ }^{14}$ found that changing the source of normal reference values with-

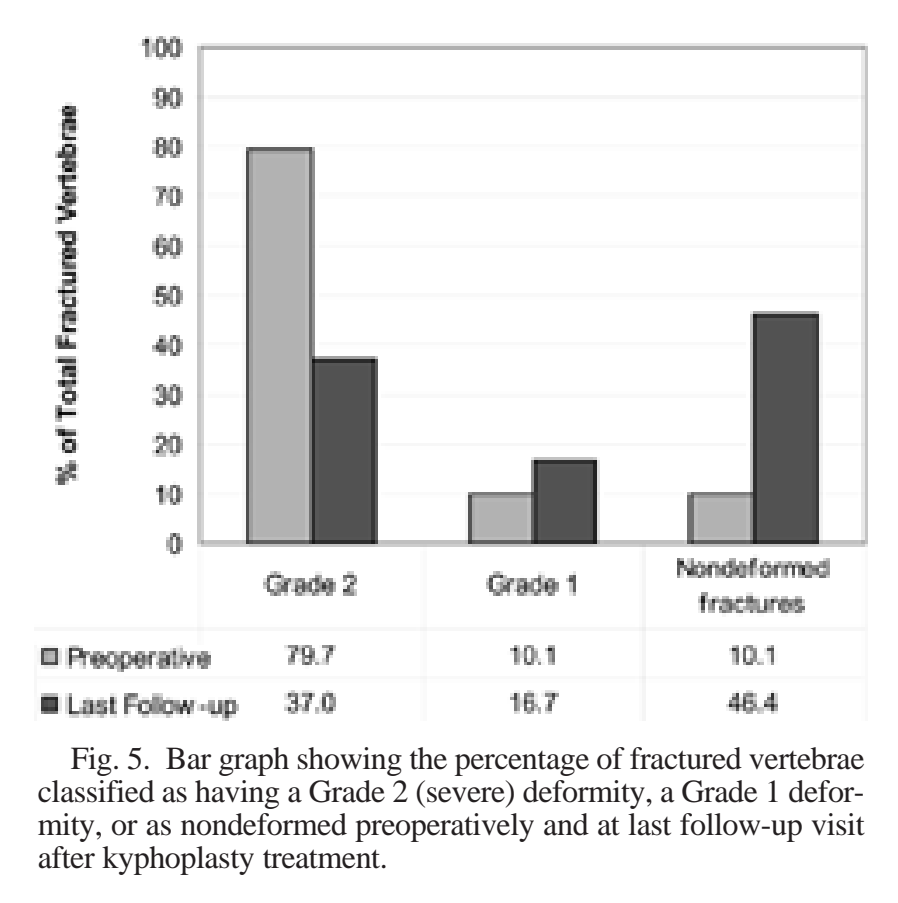

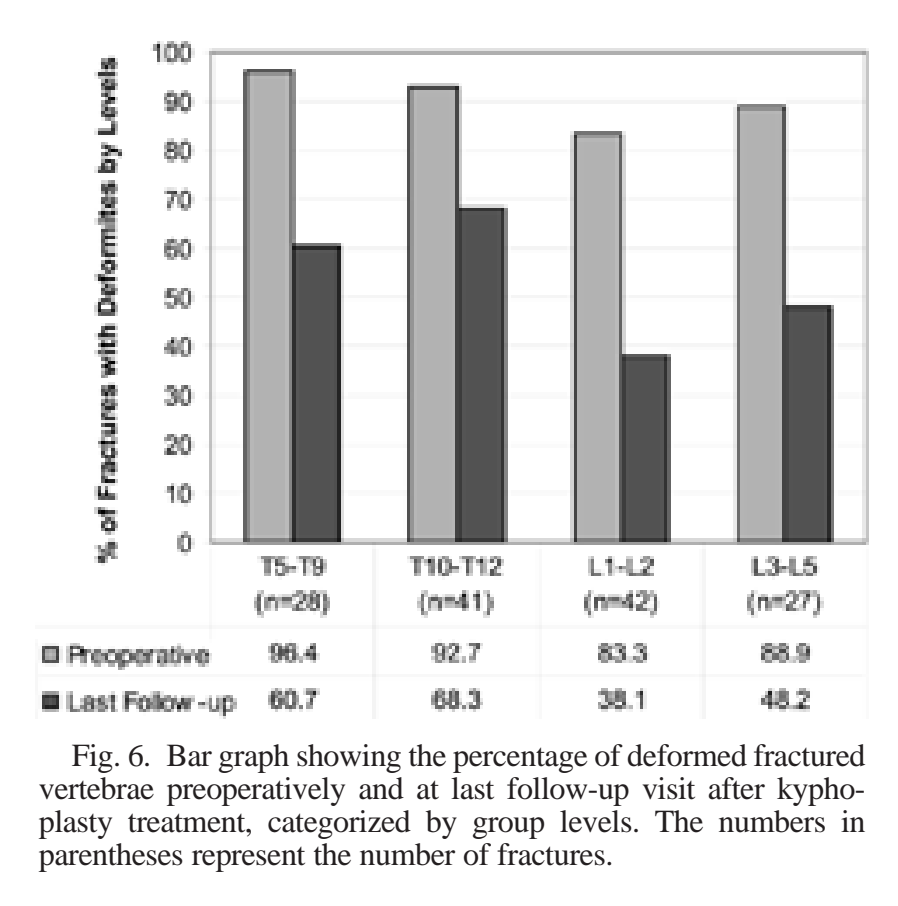

in populations from Rochester, Minnesota, by using ruler or digitized measurements, or by using cutoff values of $15 \%$ or 3 SDs, had little impact on the prevalence and incidence of deformity. Other comparisons among methods have found similar prevalences, despite different approaches in defining reference values and different methods of defining deformity. 2,14,20,23,24 Our study was not necessarily or exclusively evaluating absolute prevalence of fractures in the population, but was evaluating a treatment effect and therefore the change between two time points. Nonetheless, we closely followed previous methods of defining deformity to allow comparability with earlier studies. By using adjacent, unfractured vertebrae as references, the values are very specific to this population and the method takes advantage of the tendency of neighboring vertebrae to be similar in shape. The adjusted grouped reference values and SDs in this study closely resembled published values. ${ }^{1,13,17}$

\section{CONCLUSIONS}

Multiple studies have correlated increased morbidity and mortality rates with increased severity of spinal deformity, and it may be possible that the reduction of an individual vertebra's deformity can have a positive impact on these trends. We believe that the methods used to document changes in vertebral deformity resulting from kyphoplasty that are described here could be used to address this important question in future studies. Although the findings are not statistically significant, these data seem to indicate that lumbar vertebral deformities may be more easily corrected by kyphoplasty than thoracic ones. Additionally, because all the nondeformed vertebral fractures were less than 107 days old, earlier intervention with kyphoplasty may prevent fracture degeneration into a morphometrically discernible deformity. A similar multicenter analysis of a much larger group of patients treated with kyphoplasty is currently in progress. 


\section{Disclaimer}

Dr. Ledlie is a consultant of Kyphon, Incorporated, but he has no financial interest in the company.

\section{References}

1. Black DM, Cummings SR, Stone K, et al: A new approach to defining normal vertebral dimensions. J Bone Min Res 6: 883-892, 1991

2. Black DM, Palermo L, Nevitt MC, et al: Comparison of methods for defining prevalent vertebral deformities: the Study of Osteoporotic Fractures. J Bone Miner Res 10:890-902, 1995

3. Cortet B, Roches E, Logier R, et al: Evaluation of spinal curvatures after a recent osteoporotic vertebral fracture. Joint Bone Spine 69:201-208, 2002

4. Eastell R, Cedel SL, Wahner HW, et al: Classification of vertebral fractures. J Bone Miner Res 6:207-215, 1991

5. Ensrud KE, Thompson DE, Cauley JA, et al: Prevalent vertebral deformities predict mortality and hospitalization in older women with low bone mass. Fracture Intervention Trial Research Group. J Am Geriatr Soc 48:241-249, 2000

6. Ettinger B, Black DM, Nevitt MC, et al: Contribution of vertebral deformities to chronic back pain and disability. The Study of Osteoporotic Fractures Research Group. J Bone Miner Res 7:449-456, 1992

7. Garfin SR, Yuan HA, Reiley MA: New technologies in spine: kyphoplasty and vertebroplasty for the treatment of painful osteoporotic compression fractures. Spine 26:1511-1515, 2001

8. Hasserius R, Karlsson MK, Nilsson BE, et al: Prevalent vertebral deformities predict increased mortality and increased fracture rate in both men and women: a 10-year population-based study of 598 individuals from the Swedish cohort in the European Vertebral Osteoporosis Study. Osteoporos Int 14:61-68, 2003

9. Ismail AA, O'Neill TW, Cooper C, et al: Mortality associated with vertebral deformity in men and women: results from the European Prospective Osteoporosis Study (EPOS). Osteoporos Int 8:291-297, 1998

10. Ledlie JT, Renfro M: Balloon kyphoplasty: one-year outcomes in vertebral body height restoration, chronic pain, and activity levels. J Neurosurg Spine 98:36-42, 2003

11. Lunt M, O'Neill TW, Felsenberg D, et al: Characteristics of a prevalent vertebral deformity predict subsequent vertebral fracture: results from the European Prospective Osteoporosis Study (EPOS). Bone 33:505-513, 2003

12. Matthis C, Weber U, O'Neill TW, et al: Health impact associated with vertebral deformities: results from the European Vertebral Osteoporosis Study (EVOS). Osteoporos Int 8: 364-372, 1998

13. McCloskey EV, Spector TD, Eyres KS, et al: The assessment of vertebral deformity: a method for use in population studies and clinical trials. Osteoporos Int 3:138-147, 1993
14. Melton LJ III, Lane AW, Cooper C, et al: Prevalence and incidence of vertebral deformities. Osteoporos Int 3:113-119, 1993

15. Nakano M, Hirano N, Matsuura K, et al: Percutaneous transpedicular vertebroplasty with calcium phosphate cement in the treatment of osteoporotic vertebral compression and burst fractures. J Neurosurg Spine 97:287-293, 2002

16. O'Neill TW, Cooper C, Cannata JB, et al: Reproducibility of a questionnaire on risk factors for osteoporosis in a multicentre prevalence survey: the European Vertebral Osteoporosis Study. Int J Epidemiol 23:559-565, 1994

17. O’Neill TW, Varlow J, Felsenberg D, et al: Variation in vertebral height ratios in population studies. European Vertebral Osteoporosis Study Group. J Bone Miner Res 9:1895-1907, 1994

18. Phillips FM, Ho E, Campbell-Hupp M, et al: Early radiographic and clinical results of balloon kyphoplasty for the treatment of osteoporotic vertebral compression fractures. Spine 28: 2260-2267, 2003

19. Pluijm SM, Tromp AM, Smit JH, et al: Consequences of vertebral deformities in older men and women. J Bone Miner Res 15:1564-1572, 2000

20. Rea JA, Chen MB, Li J, et al: Morphometric X-ray absorptiometry and morphometric radiography of the spine: a comparison of prevalent vertebral deformity identification. J Bone Miner Res 15:564-574, 2000

21. Reeve J, Lunt M, Felsenberg D, et al: Determinants of the size of incident vertebral deformities in European men and women in the sixth to ninth decades of age: the European Prospective Osteoporosis Study (EPOS). J Bone Miner Res 18: 1664-1673, 2003

22. Schlaich C, Minne HW, Bruckner T, et al: Reduced pulmonary function in patients with spinal osteoporotic fractures. Osteoporos Int 8:261-267, 1998

23. Sumnik Z, Land C, Rieger-Wettengl G, et al: Effect of pamidronate treatment on vertebral deformity in children with primary osteoporosis. A pilot study using radiographic morphometry. Horm Res 61:137-142, 2004

24. Szulc P, Munoz F, Marchand F, et al: Similar prevalence of vertebral fractures despite different approaches to define reference data. Bone 32:441-448, 2003

25. Weber K, Lunt M, Gowin W, et al: Measurement imprecision in vertebral morphometry of spinal radiographs obtained in the European Prospective Osteoporosis Study: consequences for the identification of prevalent and incident deformities. $\mathbf{B r} \mathbf{J}$ Radiol 72:957-966, 1999

Manuscript received January 14, 2005.

Accepted in final form February 24, 2005.

Address reprint requests to: Jon T. Ledlie, M.D., Tyler Neurosurgical Associates, PA, 700 Olympic Plaza, Suite 850, Tyler, Texas 75701. email: jledlie@tylerneuro.com. 